\title{
Effect of Metal Ion on Ammonium Bicarbonate Solution Decomposed into Carbon Dioxide
}

\author{
Lu HU \\ School of Chemistry and Environmental Engineering, \\ Jianghan University \\ Wuhan 430056,China \\ Mei JIN \\ School of Chemistry and Environmental Engineering, \\ Jianghan University \\ Wuhan 430056,China
}

\author{
Hai-feng LI \\ School of Chemistry and Environmental Engineering, \\ Jianghan University \\ Wuhan 430056,China \\ Guo-xian YU* \\ School of Chemistry and Environmental Engineering, \\ Jianghan University \\ Wuhan 430056, China \\ Correspond email : guoxianyu828@yahoo.com.cn
}

\begin{abstract}
Ammonia-based carbon capture process is one of the promising technologiesfor $\mathrm{CO}_{2}$ mitigation. However, it has a problem to be solved for practical implementation due to the high volatilityof ammonia, which incurs ammonia lose during regeneration. Effects of $\mathrm{Fe}^{3+}$ or $\mathrm{Co}^{2+}$ on ammonia escape and $\mathrm{CO}_{2}$ desorption in $\mathrm{NH}_{4} \mathrm{HCO}_{3}$ solution decomposition processwere investigated. The results showed that, the addition of metal ion noticeably decreased ammonia escape and slightly increased desorption proportion due to the complexation of metal ion and free ammonia.The metal ion added also promoted desorption rate in this process. Moreover, metal ion $\mathrm{Fe}^{3+}$ is more effective than $\mathrm{Co}^{2+}$ on $\mathrm{CO}_{2}$ desorption and ammonia escape in the regeneration process.
\end{abstract}

Keywords- $\mathrm{Fe}^{3+} ; \mathrm{Co}^{2+}$; ammonium bicarbonate; desorption; ammonia escape

\section{INTRODUCTION}

Carbon dioxide $\left(\mathrm{CO}_{2}\right)$ is considered to be themain contributing factor to global warming and climate change, $\mathrm{CO}_{2}$ capture technologies have started getting attention[1],2].Aqueous ammonia-based $\mathrm{CO}_{2}$ capture technology has many technical and economical advantages over amine-based capture technology, such as high $\mathrm{CO}_{2}$ absorption capacity, low regeneration energy, no sorbent degradation, cheap chemical cost,and simultaneous capture of multiple pollutants[3]-10]. However ammonia absorbent has a limitation in practical application because of its high vapor pressure, which causes highloss of ammonia in regeneration process[11]. This leads to considerable loss of ammonia and requires high cost to make up ammonia inpractical implementation. Therefore, it is necessary to take appropriate measures to reduce ammonia loss and improve the economic performance.

Some measures have been reported to reduce ammonia lose, such as multistage water washing and adding organic or inorganic additives[12],13]. The former is a traditional method, and affects thewater balance and consumes more energy. Metal ion additives, such as copper and zinc,have been proposed to suppress ammonia escape through their strong complexation with $\left.\mathrm{NH}_{3}[14], 15\right]$.

In our work, the transition metals $\mathrm{Co}(\mathrm{II})$ and $\mathrm{Fe}(\mathrm{III})$ were choose to reduce ammonia loss by making use of their complexation capability with $\mathrm{NH}_{3}$. Ourexperimental work used ammonium bicarbonate solution to carry a regeneration and investigated the effect of metal types and metal concentration on the ammonia escape and $\mathrm{CO}_{2}$ desorption in the regeneration, and Ultraviolet absorption spectrum was used to characterize metal complexation with $\mathrm{NH}_{3}$. We hope that this study can facilitate the development of a novel method for suppressing $\mathrm{NH}_{3}$ volatilisation inammonia-based $\mathrm{CO}_{2}$ capture process.

\section{EXPERIMENTAL}

\section{A. Reagent}

Experimental reagent: $\mathrm{NH}_{4} \mathrm{HCO}_{3}$ (AR), $\mathrm{NaOH}$ (AR), $\mathrm{FeCl}_{3} \cdot 6 \mathrm{H}_{2} \mathrm{O}(\mathrm{AR}), \mathrm{CoCl}_{2} \cdot 6 \mathrm{H}_{2} \mathrm{O}$ (AR), anhydrous calcium chloride (AR) were purchased from Sinopharm Chemical Reagent Co.,Ltd, Concentrated sulphuric acid (AR) was purchased from Xinyang Chemical Reagent Co.,Ltd, $\mathrm{N}_{2}$ (99.9\%v) was purchased from Wuhan Huaerwen Industrial Co.,Ltd.

\section{B. Experimental System}

Self-assembled desorption experimental system was used in the experiment, which is shown inFig. 1. 250ml three necks flask was used as the desorption reactor, and it was fixed in a magnetic and thermostatic water bath (DF-101S, Henan Yuhua Instrument Co.,Ltd.,China).100ml of $\mathrm{NH}_{4} \mathrm{HCO}_{3}$ with a concentration of $1.0 \mathrm{~mol} / \mathrm{L}$ was the reactant of this decomposition process. The decomposed gas was diluted and carried out by a stable $\mathrm{N}_{2}, \mathrm{~N}_{2}$ flowrate was $0.8 \mathrm{~L} / \mathrm{min}$, and which was controlled by a mass flowmeter(MT50-3J, Beijing HORIBA METRON Instruments Co., Ltd.China). The condenser pipe was used to cool the gas out of the solution, and thus made sure water vapor would not be taken out. Then escapedNH $\mathrm{N}_{3}$ gas was 
absorbed by $50 \mathrm{ml}$ of $1 \mathrm{~mol} / \mathrm{L}$ dilute sulphuric acid when the gasmixture went through the acid pickling bottle. $\mathrm{CO}_{2}$ concertration of the gaswas measured by a GC analyzer (SP-6890, Shandong Lunan Rainbow Chemical Instrument Co.,Ltd.,China) after which was dried by the $\mathrm{CaCl}_{2}$ drying bottle. $\mathrm{NH}_{3}$ concertration of the gaswas represented by the concertration of acid from the acid pickling bottle,the concertration of acid was measured byacid-base titration method. Detail donditions of experiments was shown inTABLE1.

TABLE1EXPERIMENTAL CONDITIONS

\begin{tabular}{cc}
\hline Items & Value \\
\hline Conccentration of $\mathrm{NH}_{4} \mathrm{HCO}_{3}$ solution & $1.0 \mathrm{~mol} / \mathrm{L}$ \\
Volume of $\mathrm{NH}_{4} \mathrm{HCO}_{3}$ solution & $100 \mathrm{ml}$ \\
Temperature & $70{ }^{\circ} \mathrm{C}$ \\
$\mathrm{N}_{2}$ flowrate & $0.8 \mathrm{~L} / \mathrm{min}$ \\
Magnetic stirring speed & $200 \mathrm{r} / \mathrm{min}$ \\
Metal concentration & $0-0.03 \mathrm{~mol} / \mathrm{L}$ \\
\hline
\end{tabular}

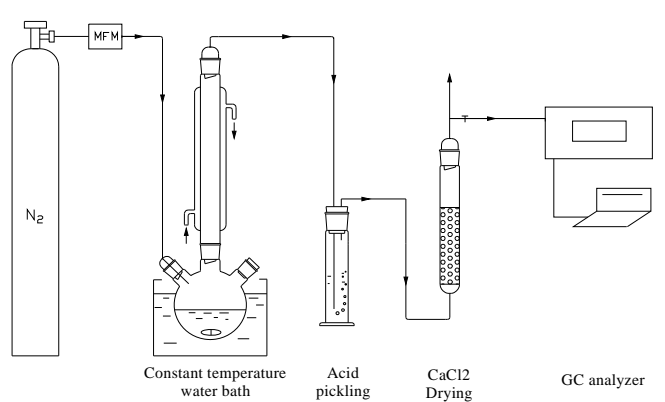

Fig. 1Experimental system of Ammonium bicarbonate decomposition

\section{RESULTS AND DISCUSSION}

\section{A. Effect of Metal Type on $\mathrm{CO}_{2}$ Flow and Desorption Proportion in the Regeneration}

Effect of metal type on $\mathrm{CO}_{2}$ flow was shown in Fig. 2a. There are 2 kinds of solution containing the same molar concentration of metal, and the other kind does not contain any metal. 3 kinds of ammonium bicarbonate solution contain the same concentration of solute. $\mathrm{CO}_{2}$ flow was recorded during the reaction from starting up to 60 min,and it is seen that the flow of $\mathrm{CO}_{2}$ desorbed from the solution fast increased first and decreased later, reaching the maximum at about $2 \mathrm{~min}$, and from $2 \mathrm{~min}$ to $10 \mathrm{~min}$ the flow fast decreased and then did very slowly until $60 \mathrm{~min}$. From the height of the curve to the time axis, from starting up to $10 \mathrm{~min}$, the order of the flow of $\mathrm{CO}_{2}$ desorbed is as follows: $\mathrm{Fe}^{3+}>\mathrm{Co}^{2+}>$ without any metal.

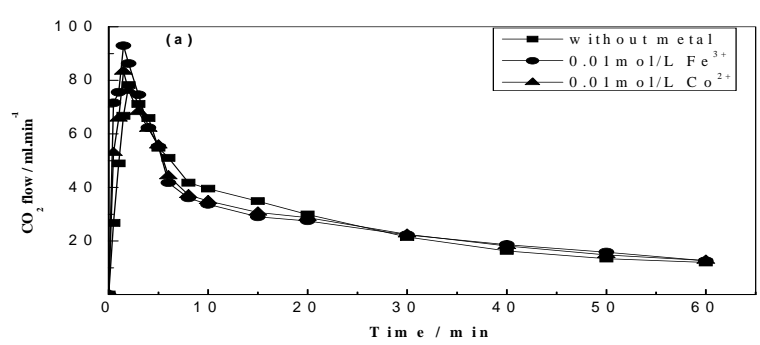

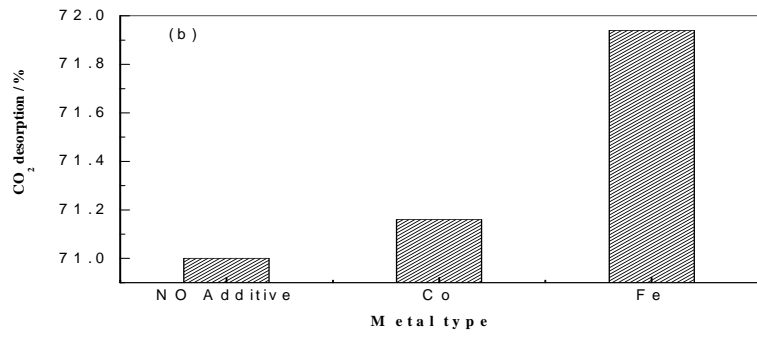

Fig. 2Effect of metal type on $\mathrm{NH}_{4} \mathrm{HCO}_{3}$ decomposition

Effect of metal type on $\mathrm{CO}_{2}$ desorption proportion was shown in Fig. 2b. It can be seen, $\mathrm{CO}_{2}$ desorption proportion was enhanced by the addition of metal, and the proportion with $\mathrm{Fe}^{3+}$ is higher than that with $\mathrm{Co}^{2+}$. Desorption proportion of the blank $\mathrm{NH}_{4} \mathrm{HCO}_{3}$ solution was found to be 7Fig. $21.0 \%$ at $70{ }^{\circ} \mathrm{C}$ and that with $\mathrm{Co}^{2+}$ was increased by $0.16 \%$ and that with Fe was increased by $0.94 \%$.

There is a reversible reaction between $\mathrm{NH}_{4} \mathrm{HCO}_{3}$ and $\mathrm{NH}_{3}, \mathrm{H}_{2} \mathrm{O}$ and $\mathrm{CO}_{2}$ in the ammonium bicarbonate solution, and metal ion in the solution, such as $\mathrm{Fe}^{3+}$ and $\mathrm{Co}^{2+}$, can produce stable complexes with free ammonia in the solution, which leads to the reaction moving to the right. $\mathrm{FeCl}_{3}$ and $\mathrm{CoCl}_{2}$ were used to investigate the effect of transitional metal ion on the regeneration. Chlorinespecies has little effect on $\mathrm{CO}_{2}$ desorption[16], so the effect of $\mathrm{Cl}^{-}$on $\mathrm{CO}_{2}$ desorption can be neglected. According to Fig.2a and Fig.2b, the results showed that the transitional metal can enhance $\mathrm{CO}_{2}$ desorption rate and proportion by adding it to the solution, and the higher the valence state of the transition metal ions is, the better promoting efficiency is.

\section{B. Effect of Metal Type on Ammonia Escape in the Regeneration}

Effect of metal type on ammonia escape was shown in Fig. 3.It can be seen, in 20 minutes, ammonia escape seemed to be no different, but from $20 \mathrm{~min}$ to $60 \mathrm{~min}$, ammonia eacape was decreased by the additive of metal obviously. And ammonia eacape with $\mathrm{Fe}^{3+}$ is lower than that with $\mathrm{Co}^{2+}$. Compared with no additive, ammonia escape was decreased by $4.90 \%$ with $\mathrm{Co}^{2+}$ and that with $\mathrm{Fe}^{3+}$ was decreased by $5.94 \%$.

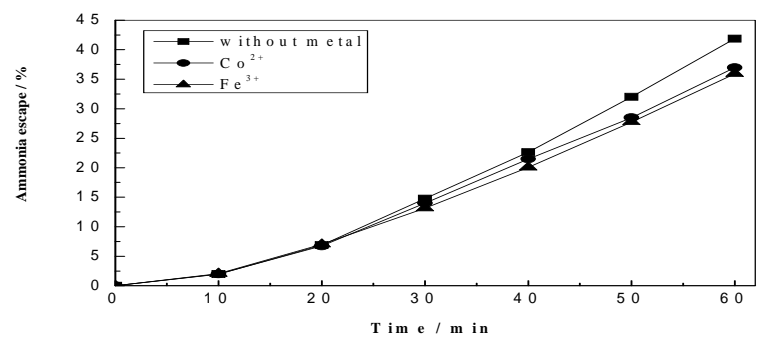

Fig. 3Effect of metal type on ammonia escape

Metal ion added can complex with free ammonia to form aintermediate product $\left[\operatorname{Metal}\left(\mathrm{NH}_{3}\right) \mathrm{x}\right]^{\mathrm{n}+}$, which reduced free ammonia concentration effectively in the 
solution, thus reducing ammonia escape. According to Fig.3, transition metal ion $\mathrm{Co}^{2+}$ and $\mathrm{Fe}^{3+}$ might both have the ability to complex with free ammonia in the solution to decrease ammonia escape. And under these conditions, $\mathrm{Fe}^{3+}$ seems to be more effective than $\mathrm{Co}^{2+}$ in ammonia control.

\section{Effect of Metal Concentration on $\mathrm{CO}_{2}$ Flow and Desorption Proportion in the Regeneration}

Effect of $\mathrm{Fe}^{3+}$ concentration on $\mathrm{CO}_{2}$ flow was shown inFig. 4a. $\mathrm{CO}_{2}$ flow was recorded during the reaction from starting up to $60 \mathrm{~min}$. It can be seen, $\mathrm{CO}_{2}$ flow increased first and decreased laterwith the increasing of $\mathrm{Fe}^{3+}$ concentration from 0 to $0.03 \mathrm{~mol} / \mathrm{L}$ the solution, reaching the maximum at about 2 min. Compared with no additive, $\mathrm{Fe}^{3+}$ added can accelerate the desorption rate in the beginning of reaction, and the higher $\mathrm{Fe}^{3+}$ concentration was, the greater the desorption rate was. Effect of $\mathrm{Co}^{2+}$ concentration on $\mathrm{CO}_{2}$ flow was shown inFig. 4b, and the $\mathrm{Co}^{2+}$ concentration effect is similar to $\mathrm{Fe}^{3+}$.
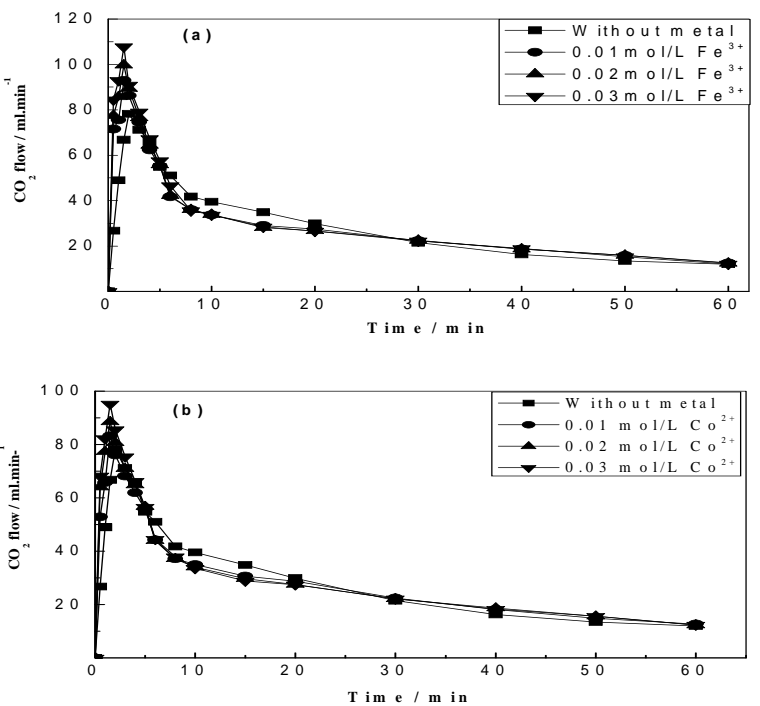

Fig. 4Effect of metal concentration on $\mathrm{CO}_{2}$ flow

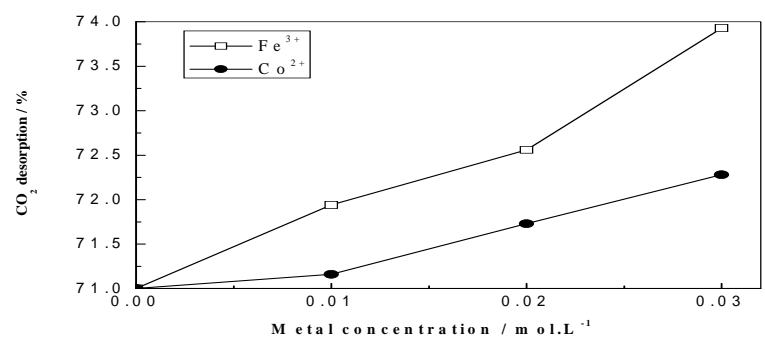

Fig. 5Effect of metal concentration on $\mathrm{CO}_{2}$ desorption

Effect of metal concentration on $\mathrm{CO}_{2}$ desorption proportion was shown inFig. 5. It can be seen, $\mathrm{CO}_{2}$ desorption was improved with the increasing of metal concentration, and desorption proportion with $\mathrm{Fe}^{3+}$ was higher than that with $\mathrm{Co}^{2+}$ generally. It was probably because the higher metal concentration was, the more free ammonia complexed, the greater desorption proportion was.

\section{Effect of Metal Concentration on Ammonia Escape in the Regeneration}

Effect of metal concentration on ammonia escape was shown inFig. 6. It can be seen that ammonia escape increased with the increasing of time. Also, compared with no additive, metal additive significantly decreased the amount of ammonia escape. The higher concentration of metal additive was, the less ammonia escape was. Accordding to the Fig. $6 a$ and Fig. 6b, under the experimental condition, ammonia escape of theblank $\mathrm{NH}_{4} \mathrm{HCO}_{3}$ solution in 60 min was found to be $41.86 \%$, that with $\mathrm{Fe}^{3+}$ which concentration from $0.01 \mathrm{~mol} / \mathrm{L}$ to $0.03 \mathrm{~mol} / \mathrm{L}$ was decreased by $5.94 \%, 6.68 \%, 8.17 \%$, and that with $\mathrm{Co}^{2+}$ was decreased by $4.93 \%, 5.93 \%, 6.89 \%$.
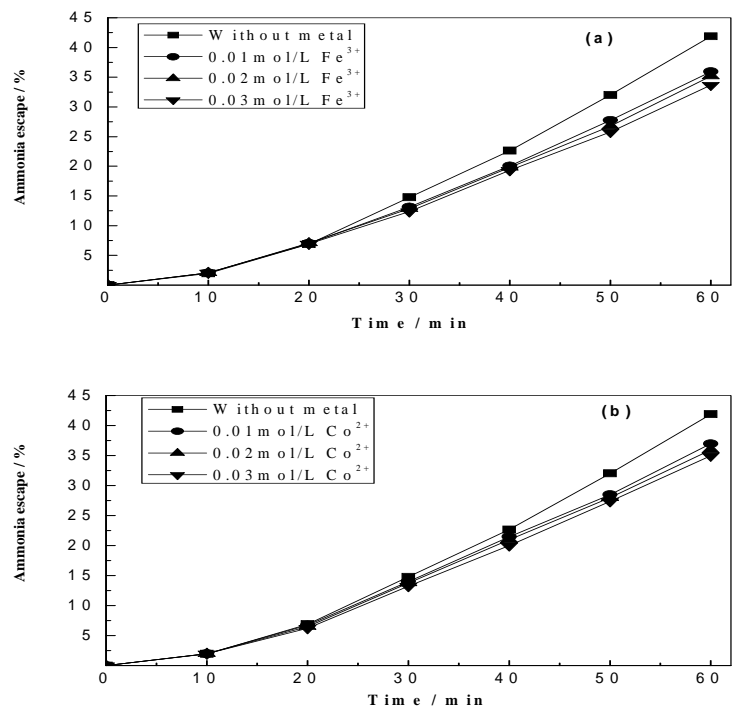

Fig. 6Effect of metal concentration on ammonia escape

\section{E. UV-Vis Characterization}

Analysis results of ammonia water, $0.01 \mathrm{~mol} / \mathrm{L} \mathrm{FeCl}_{3}$ solution, and the mixture of both was shown in Fig. 7a, that of ammonia water, $0.01 \mathrm{~mol} / \mathrm{L} \mathrm{CoCl}_{2}$ solution, and the mixture of both was shown in Fig. 7b. Compared with pure ammonia solution, the solution mixing with $\mathrm{FeCl}_{3}$ and $\mathrm{CoCl}_{2}$ had a significant increase in UV absorption intensity, indicating that its chromophore differs from the ammonia solution. The reasons are that $\mathrm{Fe}^{3+}$ and $\mathrm{Co}^{2+}$ complex with $\mathrm{NH}_{3}$ to form $\left[\mathrm{Fe}\left(\mathrm{NH}_{3}\right)_{6}\right]^{3+}$ and $\left[\mathrm{Co}\left(\mathrm{NH}_{3}\right)_{6}\right]^{2+}$, causing the absorption intensity increase[17]. Therefore it can be determined that $\mathrm{Fe}^{3+}$ and $\mathrm{Co}^{2+}$ can complex with free ammonia in solution, thereby reducing ammonia volatilization. 

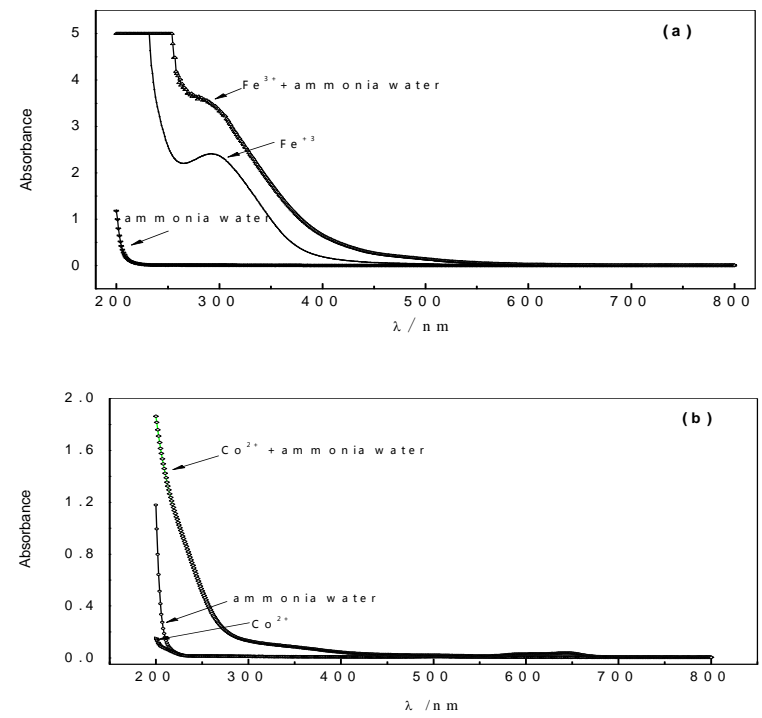

Fig. 7Ultraviolet absorption spectrum

\section{CONCLUSIONS}

Effects of $\mathrm{Fe}^{3+}$ or $\mathrm{Co}^{2+}$ on ammonia escape and $\mathrm{CO}_{2}$ desorption in $\mathrm{NH}_{4} \mathrm{HCO}_{3}$ solution decomposition process were investigated in this work. The results showed that the desorption proportionprocess was promoted and ammonia escape of that was inhibited by adding $\mathrm{Fe}^{3+}$ or $\mathrm{Co}^{2+}$ due to the complexation of metal and ammonia. Uv-vis spectrophotometer was used to verify ammonia escape inhibition mechanism. Meanwhile, metal additive added can accelerate the desorption rate, thus reduce desorption time and energy comsumption. Two kinds of additive used in this study, $\mathrm{Fe}^{3+}$ is better than $\mathrm{Co}^{2+}$ in $\mathrm{CO}_{2}$ desorption proportion and ammonia escape control.

\section{ACKNOWLEDGMENT}

This work was financially supported by Wuhan Planning Project of Science and Technology (No. 20150617 01011597).

\section{REFERENCES}

[1] HanK., AhnC.K., LeeM.S., RheeC.H., KimJ.Y.,ChunH.D.Current status and challenges of the ammonia-based $\mathrm{CO}_{2}$ capture technologies toward commercialization.International Journal of Greenhouse Gas Control Vol.14(2013) 270-281.

[2] MondalM.K.,BalsoraH.K., VarshneyP.Progress and trends in CO2 capture/separation technologies: a review. Energy Vol. 46(2012)431-441.

[3] Valenti G., Bonalumi D.,Maeehi E. Energy and energy analyses for the carbon capture with the Chilled Ammonia Process(CAP). $9^{\text {th }}$ International Conference on Greenhouse Gas Control Technologies, Washington DC, 2009.

4] Resnik K.P., Garber W. Hreha D.C. A parametric scan for regenerative ammonia-based scrubbing for the capture of $\mathrm{CO}_{2}$. Proceedings of 23rd Annual International Pittsburgh Coal Conference,Pittsburgh, PA, 2006.

[5] Carol T.M., Chakib B. Assessment of different methods of $\mathrm{CO}_{2}$ capture in post-combustion using ammonia as solvent. Journal of Cleaner Production Vol.103(2015) 463-468.

[6] Darde V. Experimental measurement and modeling of the rate of absorption of carbon dioxide by aqueous ammonia.International Journal of Greenhouse Gas Control Vol. 5(2011)1149-1162.

[7] Darde V, Willy J.M., Well V. $\mathrm{CO}_{2}$ capture using aqueous ammonia: kinetic study and process simulation. Energy Procedia Vol.4 (2011) 1443-1450.

[8] Zhang M., Guo Y. Process simulations of large-scale $\mathrm{CO}_{2}$ capture in coal-fired power plants using aqueous ammonia solution. International Journal of Greenhouse Gas Control Vol.16 (2013) 61-71.

[9] Yu H., Qi G.J., Wang S.J., MorganS., Allport A., Cottrell A., Do T., McGregor J.,Wardhaugh L., Feron P.. Results from trialling aqueous ammonia-basedpost-combustion capture in a pilot at Munmorah Power Station: gas purityand solid precipitation in the stripper. International Journal of Greenhouse GasControl Vol.10 (2012) 15-25.

[10] YuH., Xiang Q., Fang M., Yang Q., Feron P. Promoted CO2absorption inaqueous ammonia. Greenhouse Gases: Science and Technology (2013) 200-208.

[11] Budzianowski W., Koziol A. Stripping of ammonia from aqueous solutionsin the presence of carbon dioxide: effect of negative enhancement of mass transfer. Chem. Eng. Res. Des. Vol.83 (2005) 196-204.

[12] Budzianowski W.M. Mitigating NH3 vaporization from an aqueous ammonia process for $\mathrm{CO}_{2}$ capture. Int. J. Chem. React. Eng (2011) 9.

[13] Ma S., Song H., Wang M., Yang J., Zang Bin. Research on mechanism of ammonia escaping and control in the process of CO2capture using ammonia solution. Chemical Engineering Research and Design Vol.91 (2013) 1327-1334.

[14] Yoori Kim., Seong-Rin Lim., Jong Moon park.The effects of Cu(II) ion as an additive on $\mathrm{NH}_{3}$ loss and $\mathrm{CO}_{2}$ absorption in ammonia-based CO2 capture process. Chemical Engineering Journal,Vol.211/212 (2013) 327-335

[15] Kangkang Li., Hai Yu., Moses Tade., Paul Feron. Theoretical and experimental study of NH3 suppression by addition of Me(II) ions (Ni, $\mathrm{Cu}$ and $\mathrm{Zn}$ ) in an ammonia-based $\mathrm{CO} 2$ capture process. International Journal of Greenhouse Gas Control Vol.24 (2014) 54-63.

[16] S.C. Ma, M.X. Wang, H.H. Song, B. Zang. Influence of liquid coexisting components on CO2 desorption from decarburization absorbing solution by ammonia method, J. Fuel Chem. Technol. Vol.4 (2013) 477-484

[17] Z.T. Pan, B.H. Li, C.Y. Li. Analytical Chemistry, Science Publishing, Bei Jing, 2010 